\title{
Scripted collaboration in serious gaming for complex learning: Effects of multiple perspectives when acquiring water management skills
}

Citation for published version (APA):

Hummel, H., Nadolski, R., Kurvers, H., Löhr, A., Van Houcke, J., \& Van der Hiele, T. (2010). Scripted collaboration in serious gaming for complex learning: Effects of multiple perspectives when acquiring water management skills. British Journal of Educational Technology, 42(6), 1029-1041. https://doi.org/10.1111/j.14678535.2010.01122.x

DOI:

10.1111/j.1467-8535.2010.01122.x

Document status and date:

Published: $23 / 09 / 2010$

Document Version:

Peer reviewed version

Please check the document version of this publication:

- A submitted manuscript is the version of the article upon submission and before peer-review. There can be important differences between the submitted version and the official published version of record. People interested in the research are advised to contact the author for the final version of the publication, or visit the DOI to the publisher's website.

- The final author version and the galley proof are versions of the publication after peer review.

- The final published version features the final layout of the paper including the volume, issue and page numbers.

Link to publication

\section{General rights}

Copyright and moral rights for the publications made accessible in the public portal are retained by the authors and/or other copyright owners and it is a condition of accessing publications that users recognise and abide by the legal requirements associated with these rights.

- Users may download and print one copy of any publication from the public portal for the purpose of private study or research.

- You may not further distribute the material or use it for any profit-making activity or commercial gain

- You may freely distribute the URL identifying the publication in the public portal.

If the publication is distributed under the terms of Article $25 \mathrm{fa}$ of the Dutch Copyright Act, indicated by the "Taverne" license above, please follow below link for the End User Agreement:

https://www.ou.nl/taverne-agreement

Take down policy

If you believe that this document breaches copyright please contact us at:

pure-support@ou.nl

providing details and we will investigate your claim.

Downloaded from https://research.ou.nl/ on date: 26 Apr. 2023 


\title{
Scripted collaboration in serious gaming for complex learning: Effects of multiple perspectives when acquiring water management skills
}

\author{
Hans G. K. Hummel, Jasper van Houcke, Rob J. Nadolski, Tony van der Hiele, \\ Hub Kurvers and Ansje Löhr
}

Hans G. K. Hummel is an associate professor at the Open University of the Netherlands, the Netherlands. Jasper van Houcke is a lecturer in the HZ University of Applied Science, the Netherlands. Rob J. Nadolski is an assistant professor at the Open University of the Netherlands, the Netherlands. Tony van der Hiele is a lecturer in the HZ University of Applied Science, the Netherlands. Hub Kurvers is a software programmer in the Open University of the Netherlands, the Netherlands. Ansje Löhr is an assistant professor at the Open University of the Netherlands, the Netherlands. Address for correspondence: Hans G. K. Hummel, Centre for Learning Sciences and Technologies (CELSTEC) of the Open University of the Netherlands (OUNL), Valkenburgerweg 177, 6419 AT Heerlen, the Netherlands. Email: hans.hummel@ou.nl

\begin{abstract}
This paper examines how learning outcomes from playing serious games can be enhanced by including scripted collaboration in the game play. We compared the quality of advisory reports, that students in the domain of water management had to draw up for an authentic case problem, both before and after collaborating on the problem with (virtual) peer students. Peers studied the case from either an ecological or governance perspective, and during collaboration both perspectives had to be confronted and reflected upon. This paper argues why such type of workplace-based learning scenarios are important for professional development, describes how serious gaming scenarios can be designed to support such complex learning, and reports data on student satisfaction and learning effects of including scripted collaboration. Preliminary results from a pilot study with 12 students show that including scripted collaboration significantly enhances the quality of learning outcomes.
\end{abstract}

\section{Collaboration and serious games for complex learning}

Serious games are games that can educate, train or inform, either because they have been deliberately designed for learning or just happen to do so by coincidence. Educators call them 'serious' to denote that they are not just fun to play, but also hold potential as cognitive tools for learning and professional development (eg, Michael \& Chen, 2006; Prensky, 2006; Rayburn, 2007). Serious games are supposed to offer many new learning opportunities and positive effects on learner motivation and learning outcomes (eg, De Freitas, 2006; Kiili, 2007; Shaffer, 2006). As opposed to serious games, leisure (or amusement) games have already become adopted widely by the new generation of learners. The leisure games industry and educational institutes so far barely have worked together, and continue to act from separated worlds and objectives. The mind set on learning exudes an air of calm reflection, concentration and investigation, while the mind set on gaming is driven by amusement, fast fun and relaxation. Also, to counterbalance this presumed contradiction, educators have started using the term 'serious games' to indicate that games can be both instructive and meaningful for learning, and playful and fun at the same time. 
Serious games can provide immersive learning opportunities. Some appear crucial for competences required for modern citizens and professionals in business and industry in the current information age. Learning can no longer remain restricted to acquiring knowledge of content matter, but also has to deal with selecting and using this knowledge for certain problem situations in the workplace. Such more complex learning is about acquiring competences like information skills, media literacy, problem-solving, communication and collaboration, and critical reflection about wicked problems. Such competences are usually not addressed by other learning platforms (Gee, 2003). The objective of this study was to see how collaboration scripts within serious games can foster these types of more complex workplace-based learning. We hypothesise that (1) inclusion of collaborative scripts increases the quality of learning output, and that (2) these virtual learning environments are appreciated by students.

Today's professionals will become lifelong learners that continuously have to face problem situations that are changing dynamically and rapidly. Furthermore, organisations' tacit knowledge plays a crucial role in solving their problems, but such knowledge can only be expressed and accessed by communicating about and collaborating on authentic tasks. The absence of the effect of collaboration on solitary (single-user) games has been found in various contexts, where it prompted the development of multiplayer games including scripted collaboration. Multiplayer and multi-role games can enable and provoke social learning and collaborative task activity, rather than just provide learners individual access to codified knowledge of content matter.

Collaboration can either be about the game (and take place in a face-to-face context) or be an integral part of the online game (and take place in a virtual context). In the latter case, such collaboration has to be enabled by the script, game play or didactic scenario, which in this paper will be denoted by 'scripted collaboration'. These serious games will use the situated context (or authentic case) and have learners access tacit knowledge, as well as share and co-construct new knowledge together (Bell, Kanar \& Kozlowski, 2008). Collaboration (or negotiation) scripts have been scarcely implemented within educational games so far.

This paper studies the potential of scripted collaboration within serious games in support of professional competence development. We will argue why serious gaming holds this potential and how collaboration scripts can foster professional competence development. For this purpose, we have examined the learning effects of a serious game in the domain of water management, including a collaboration script that was studied and evaluated by a small group of students. In the following paragraphs of this introduction section, we will elaborate on the role of collaboration with serious games in general, and introduce the specific collaboration script and serious game (in the domain of water management) that we used for our study. The second and third sections of the paper will then continue to present the method and main results of the case study we carried out with a small group of higher education students. Finally, the concluding section will discuss the main results on learning effects and student satisfaction, and suggest some new lines of research.

\section{Scripted collaboration and serious games}

Games are heavily inspired by the learning-by-doing principle. The way players move, progress and navigate within serious games, to a large degree, will depend on their self-explorative wayfinding behaviour and will often have a substantial trial-and-error component. Learner support should help students select the most useful information, compare and reflect on multiple perspectives, and monitor task progress and quality of learning output. This paper examines the extent to which collaboration scripts within serious games can provide such learner support, and as a consequence, improve learning output.

Collaboration within technology-enhanced learning (TEL) in general has been researched extensively, and is commonly denoted as CSCL/CSCW (computer supported collaborative 
learning/computer supported collaborative work). Computer-supported collaborative learning (CSCL) environments have shown to positively influence learning (eg, Gunawardena, Carabajal \& Lowe, 2001; Gunawardena, Lowe \& Anderson, 1997). The interaction in CSCL between learners can lead to further elaboration and refinement of individually constructed schemata, since it (1) incites learners to make explicit the actual level of schema development, and (2) demands them to explicitly compare their own schemata with schemata of others as to defend or criticise (Jeong \& Chi, 2000). However, research on collaboration and TEL generally does not involve serious games with collaboration deliberately scripted within the game play.

There are various support mechanisms that could structure collaboration during game play. From research on CSCL/CSCW, we know that Strijbos and Martens (2001) successfully added structure by presenting roles to students; Owen (2000) by setting clear boundaries in terms of time and number of contributions; Van Bruggen, Kirschner and Jochems (2002) by providing a tool to support the explicit formulation, representation and testing of hypotheses; and Beers, Boshuizen and Kirschner (2003) by providing a negotiation tool to support the process of finding common ground in problem-solving groups. De Wever, Valcke and van Winckel (2003) found that adding 'task structure' to the discussions led to higher levels of knowledge construction as measured by the levels of analysis by Gunawardena et al. (1997). In many of such collaboration scripts, players are assigned different epistemic or social roles and tasks (Hämäläinen et al., 2008; Weinberger, Ertl, Fisher \& Mandl, 2005), an approach we have also taken in our case study. Fullerton, Swain and Hoffman (2008) promote the conflict-script as suitable candidate for scripted collaboration. Such scripts (or didactic scenarios) take conflicts as starting points for learning and discovering multiple aspects and perspectives of a problem. Conflicts can entail physical or mental obstacles, different perspectives, stakeholders and/or ethical dilemmas. For instance, when setting up a new business, one partner can be made responsible to warrant that investments are sustainable and will not damage the natural environment, while another partner's main job is to guarantee that initial investments actually pay off. Besides in entrepreneurial finance, such conflicts are often found in health care, governance and policy-making, and other multi-disciplinary domains where experts from different disciplines have to work together to reach solutions and compromises, like also in water management. In our case study (to be elaborated later on), user conflicts when solving a water management problem have to be exchanged, reflected upon and integrated by both taking an ecological and governmental perspective on the case.

The main research questions of this paper and the case study it describes are: (1) Does inclusion of scripted collaboration increase the learning outcomes of the game? and (2) Do students appreciate collaboration within the game play? In other words, this paper addresses the effectiveness and appreciation of collaboration within serious gaming. Before describing the method, we used for our case study and the results we found, we now first introduce our 'case lead', an exemplary and authentic dilemma that is representative for the challenges and conflicts in workplace-based learning we discussed before, and which case stood at the base of designing the serious game on aquaculture and the collaboration script within.

Aquaculture: an exemplary collaboration script within a game on water management Aquaculture deals with the development of flora (plants) and fauna (animals) in water. Starting a new economic activity with aquaculture from scratch is not a simple endeavour, since water systems are used intensively and serve many purposes, especially in densely populated areas. To assess the influence of the new use on the system and other purposes, professionals working in the domain of water management have to both possess natural scientific knowledge and have a keen eye for the context of policy-making that is involved. Aquaculture is a relatively new sector (in the Netherlands). Governmental and licensing institutions still struggle to find their 
way in dealing with entrepreneurs that want to start new business in this sector, especially because aquaculture can become manifest in many ways and because current legislation can be contradictory and leaves room for subjective interpretation. Economic interests often do not coincide with the interest of (especially saline/marine) agriculture or recreation. Water management professionals have to deal with conflicts and dilemmas, and need to negotiate in order to reach agreement among various stakeholders involved in the development area. To assess the feasibility of new activity, professionals need extensive knowledge of water streams and water quality. The field of water management therefore is in need of professionals with a rather broad background that can approach these decisions from both an ecological (nature) and governance (policy) perspective. For these reasons, aquaculture (and especially shellfish culture) seems to be a perfect topic to be studied within higher education, and to be worked out and collaborated upon from different perspectives in an authentic gaming environment.

\section{Method}

The paragraphs in this section will describe the way we have set up our case study. After describing the participants, we describe the learning material, procedure and instruments we used to research and measure the learning effects and student appreciation of scripted collaboration.

\section{Participants}

Twelve water management students of the HZ University of Applied Science in the Netherlands participated in this case study. The serious game on aquaculture we developed has a study load of about 30 hours and is the practical part of the aquaculture course that most students follow during their third year of the Bachelor of Water Management programme. The average age of the participants was 22 years, with a range from 19-26. Seven were male and five were female students.

\section{Learning material}

The online 'Aquaculture' game was developed using the EMERGO method and toolkit for serious game development. In this paragraph, we will now subsequently describe the following: the EMERGO method and toolkit we used for its development, the collaboration script and the technical setup that enables the collaboration.

\section{EMERGO method and toolkit}

The EMERGO method emphasises first the designing and elaborating of a learning scenario before actually starting the development with the toolkit. The toolkit consists of reusable components offering various functionalities, and is especially tailored towards complex learning. The toolkit, for instance, holds independent components for making locations (that may contain resources), for actually adding the resources (both text-based and audio-visual), for making interviews (with virtual experts), for sending messages and notifications, and others. The most important component without any doubt is the Scripting-tool that actually links all other components together and determines the scenario of the game play. Scripting may consist of various if ... then ... rules, eg, 'If the student has read at least five out of ten publications on shellfish production [resources] that can be found in the library [location], then she may access the room of the project leader [location] and ask her a number of questions [interview]'. Scripting allows for a broad variety of didactical approaches, since it decides the degree to which tasks are structured in advance, the amount of learner support offered, whether and how collaboration will take place, and other mechanisms and processes. The Open Source EMERGO method and toolkit have been successfully applied to games across various domains, and are continuously being improved further. For more information, we refer to Nadolski et al. (2008) or to http://www.emergo.cc. For a first impression 

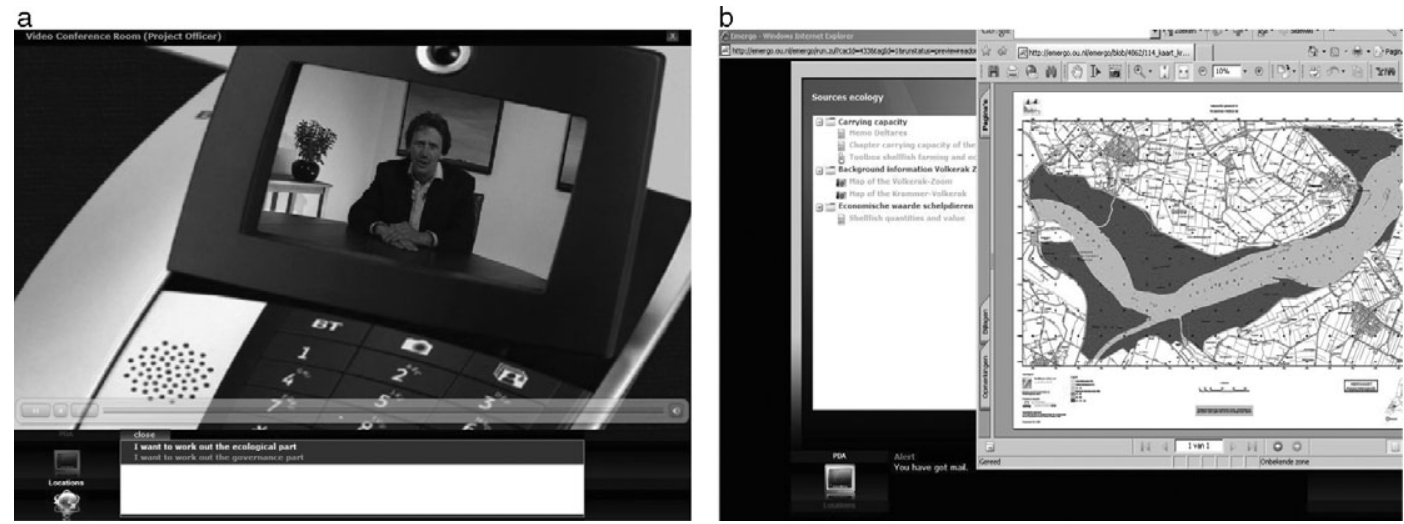

Figure 1: Case 'Aquaculture' screen dumps: (a) teleconference with supervisor, and (b) folder structure with resources

of the Aquaculture game, Figure 1 depicts two screendumps. The first picture shows the (virtual) supervisor of the international consultancy agency during a teleconference call. The second picture shows a number of resources on the personal digital assistant.

Collaboration script 'Aquaculture'

At the offset of the game, the student is assigned the role of an externally hired project leader (working at a renowned foreign consultancy agency), and is asked to get to the Netherlands to investigate and draw up a feasibility report on what would be the most suitable location to start a new shellfish production site in a saline Volkerak Zoom Lake (VZL). After becoming sufficiently oriented on the task as a project leader, the student will be asked to deliver a first version of an elaborated and argued table of contents for the report, in which both perspectives (ecological and governance) have to be represented. By this point of time students will have discovered how complex this task is, which stakeholders have to be considered, and which dilemmas play a role.

Now we get to the (virtual) collaboration part of the script. The head of the consultancy agency now asks the student (still in the role of project leader) to make a choice: to continue elaborating the report from either an ecological or governance perspective (see Figure 1a). The head takes care to fly in a (virtual) colleague who will choose the other perspective and will collaborate with the student. When the student opts for the ecological perspective the focus will be on nutrient streams and flourishing of alga, ecological possibilities and the maximum exploitation of the area; user conflicts will be left out of scope. When the student opts for the governance perspective the focus will become on various stakeholders and their demands, policy and procedures for shellfish cultivation and the VZL area; suitable species, cultivation methods and production numbers will be left out of scope. When the table of contents has been sufficiently worked out from the chosen perspective, an email with this preliminary (ie, necessarily partial) elaboration of the report is send to the (virtual) colleague for inspiration and reflection, and at the same time to the (real-life) tutor of the course for assessment. In reality, it will be the tutor that takes care that the student now receives the (also necessarily partial) elaboration from the colleague who took the other stance. Reception is guaranteed within the next 24 hours (for an already running course, the tutor might pick a worked example from a growing stack of student works). Finally, the student has to reflect on and combine both, partial elaborations that will be confronting or contradictory, in the final advisory report to be send and assessed as the individual learning outcome of this game (see Figure 2). 


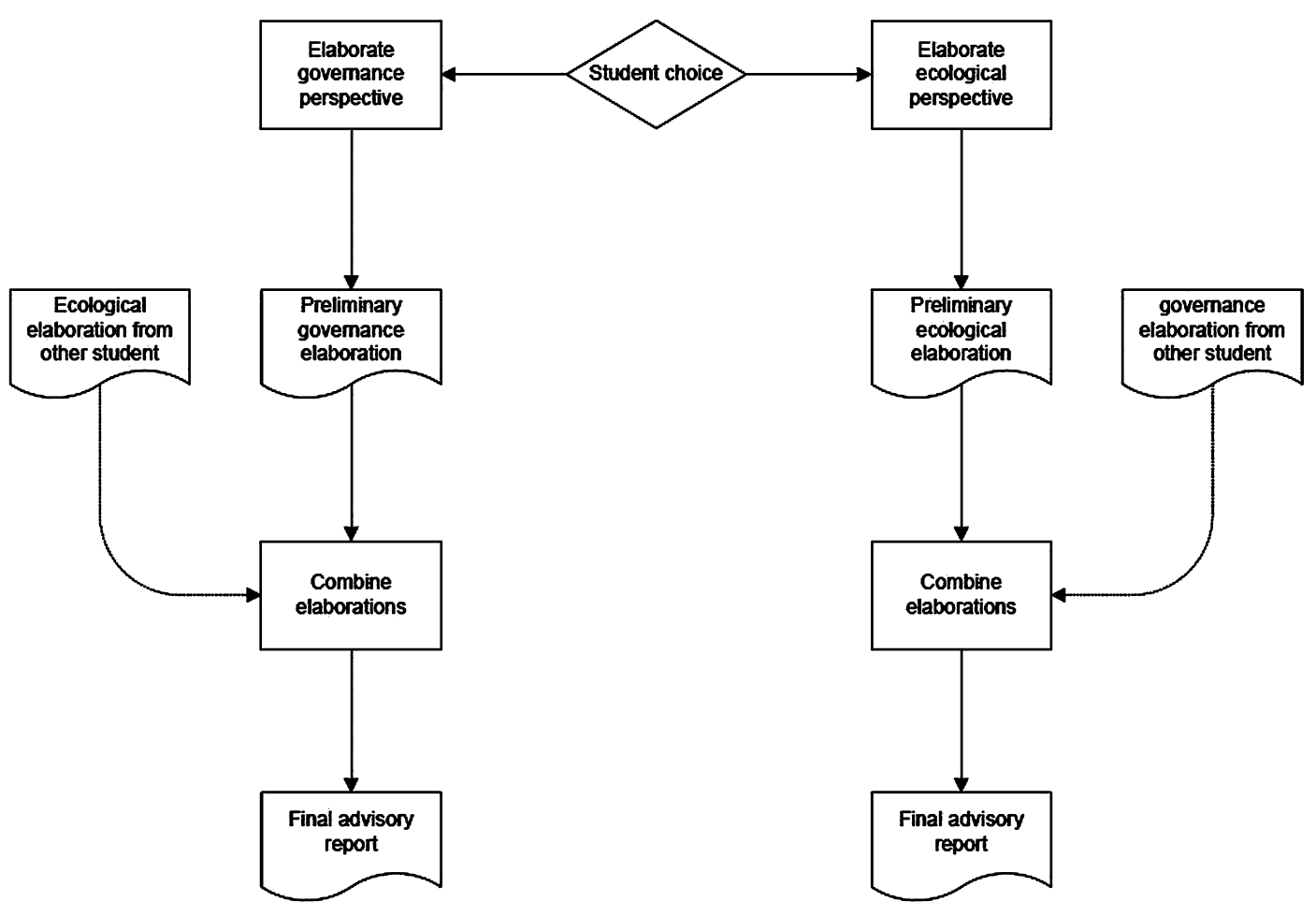

Figure 2: Collaboration script flow

Technical EMERGO setup to enable the collaboration script 'Aquaculture'

The main component involved was the scripting component of the EMERGO toolkit. Other components whose content depends on the student's choice of perspective are the interview component, the mail component, the resources component and the location component. In this case study, we added three instances of the scripting component. One instance to control the case flow common to all students, up to the point a student has to decide for the ecological or the governance perspective, one instance to deal with the ecological path, and one instance to deal with the governance path. The latter two instances are not activated at the start of a student's run. That means, the conditions they contain are not checked. Then, depending on the choice of the student, either of the two inactive instances is activated.

To allow the student to make a choice, the interview component is used. A conversation was defined in which the student's (virtual) supervisor offers the student the choice of perspective (see Figure 1a). With the resource component, a case developer can add study material such as documents, papers, video, audio, hyperlinks and the like. The resources can be organised in a tree-wise folder structure (see Figure 1b). Of course, the two extra instances are at first invisible for the student. When the student has chosen, the activated scripting component adds the corresponding resources component to the student's environment.

After the student has mailed his (partial) elaboration, he receives the elaboration of his (virtual) colleague that took the other stance. Scripting conditions allow the tutor 24 hours to send out the 'personalized' mail from the colleague. The tutor can choose from elaborations of students that already followed the other perspective, or send a worked out example. If the tutor doesn't respond within 24 hours, the worked out example will automatically be send. 


\section{Procedure and instruments}

For the this study's research purposes, the tutor of this course, being one of the coauthors, allocated one of the two perspectives to each student, mainly to warrant that (about) half of the students would take the first and the other half the second perspective. Upon the start, students were notified to have about a month to study this game (having a study load of about 30 hours) and deliver the final report, allowing them much freedom to study the case at their own pace and place. They had to be reminded and were allowed 6 weeks to conclude. Virtual collaboration on average took place after about $75 \%$ of this period. The same (real life) tutor collected, scored and compared both the preliminary (before virtual collaboration) and final (after virtual collaboration) reports, in close cooperation with another tutor (also coauthor of the paper), using a learning effect correction model. Although we did not explicitly measure the inter-subjective reliability of the correction model, both tutors assessed the reports and agreed upon the scores to be given on the various items of the model. Appreciation of the serious game was measured by online questionnaires students had to fill in at the start and at the end (ie, after sending in their final reports).

\section{Learning effect correction model}

To measure learning output while studying the online game, a correction model was developed to assess the quality of the reports sent in before and after the (virtual) collaboration. Partial elaborations (preliminary reports) before collaboration were assessed as pretest results, and integrative elaborations (final reports) after collaboration were assessed as posttest results, both by scoring this correction model. Table 1 contains the ingredients to be addressed in a perfect advisory report (yielding a maximal total score of 100 points), indicating as well what amount of points could maximally be earned for each specific ingredient. The correction model contains three parts: the ecology part (A), the governance part (B), and the integration part (C). For each perspective (A and B) an equal amount of 30 points could be earned, for the integration part $(\mathrm{C})$ an additional amount of 40 points could be earned, yielding a total of 100 points.

\section{Student satisfaction questionnaire}

The online questionnaire (using Questback) contains around 70 items to establish the students' opinion on various aspects of the serious game, pertaining to usability and user-friendliness of the game, and its contribution to attaining various learning goals. Before and after taking the course, students were asked to answer two web questionnaires (pre- and post-questionnaire). Table 2 only lists (10) items and results of direct relevance for this study from the post-questionnaire, ie, reflecting the student satisfaction with collaboration as included in the gameplay. All items were positively formulated and used a Likert scale with five values, ranging from (1) fully disagree to (4) fully agree, and an extra (fifth) value 'not apply'. The median value (neutral) therefore is 2.5 , with all values below to be interpreted as (slightly) negative and all values above as (slightly) positive appreciations.

\section{Results}

Results provide answers to our research questions posed in the introduction: (1) Does inclusion of scripted collaboration increase the learning outcomes of the game? and (2) Do students appreciate collaboration within the gameplay? We will now, respectively, present the objective learning effects measures, collected by scoring the reports before and after collaboration, and the subjective questionnaire measures, scored after completion of the serious game.

\section{Learning effects}

Table 3 shows the report scores, both before and after (virtual) collaboration, as well as the initial perspectives (with 1 = ecological, 2 = governance perspective). Upon visual inspection, it immediately becomes clear that a very significant increase can be observed between measures 
Table 1: Ingredients and maximum scores of the correction model

Subjects (ingredients)

Maximum points

(100 in total)

\section{Ecology part}

A

Map with explanation of possible locations seen in an ecological point of view

Nutriënt supply of the Brabant Rivers and Hollands Diep, resulting in algaeblooms?

Depth and bottom condition

Is the surface area of the location mentioned?

Is the map clear?

Explanation (with multi criteria analysis) of possible shellfish species:

The demands of shellfish species for its environment/habitat:

Necessary bottom condition

Required water quality

Other criteria:

Available knowledge

Availability of shellfish seed

Labour intensity of cultivation

Sensitivity for diseases and predation

Explanation of culture methods for the described shellfish species:

Seed supply (based on chosen shellfish)

Techniques for culturing (based on chosen shellfish)

Techniques for harvesting (based on chosen shellfish)

\section{Carrying capacity}

Calculations

Sources used

Conclusion: possible yield based on carrying capacity: $6-9.10^{6} \mathrm{~kg} / \mathrm{yr}$

Economic value of shellfish

Pilot 100 ha

Calculations: $1.5-4.10^{6} €$

Sources used

Long term expectation

Calculations: 10 to $23.10^{6} €$

Sources used

\section{Governance}

B

Map with explanation of searching areas for possible shellfish locations, based on:

Shipping traffic

Recreation areas

Nature conservation areas

Closed areas

Sluices and locks

Is the map clear?

Description of shellfish policies:

Dutch shellfish policy

Provincial policy (PSEB for aquaculture and fisheries)

Agreement between ministry, NGO's and farmers 
Table 1: Continued

Subjects (ingredients)

Maximum points

(100 in total)

Legislation involved
(Flora and fauna act)
Nature protection act
(Fisheries act)
Food and consumer product safety authority
Animal health and welfare act
Product organisation (advice on assigning plots to farmers)

Suitable assessment

Sources (Jaap Holstein)

Food safety and classification of production areas

Steps to take

Duration for classification

Monitoring

Decree animals kept for production purposes

List of animals

Short description of procedure for new production species:

Animal welfare

Production plan

Biological characteristics of species

Experience elsewhere

\title{
Integration
}

C

\author{
Introduction: \\ Present situation \\ Backgrounds \\ Problem definition
}
Integration:
Integrated map
Chosen shellfish $\leftarrow \rightarrow$ Decree animals kept for production purposes + policy
Suitable locations (ecology) $\leftarrow \rightarrow$ No go area's
Culture techniques $\leftarrow \rightarrow$ Policy

Final advice,

Plots to farmers

Which shellfish

Culture techniques

Locations

Steps to take + conclusion

PSEB, provincial social-economic policy plan; NGO, non-governmental organisation.

before $(M=19.92$; standard deviation $(S D)=8.47)$ and after collaboration $(M=54.00$, $S D=6.28$ ). A paired $t$-test (two-tailed) confirms the high significance of this observation $(t=-14.53 ; p<0.001)$. The most important hypothesis therefore can be confirmed: virtual collaboration indeed improves learning effect. We controlled for the influence of perspective on this learning effect (ie, on the increase of scores), which appears to be missing $(F(1,11)=0.72$, $\left.M S E=46.67, p=0.42, \eta_{p}{ }^{2}=0.07\right)$. Furthermore, diary measures and questionnaire results 
Table 2: Questionnaire items related to (virtual) collaboration within the game

\begin{tabular}{|c|c|c|c|c|c|c|c|c|}
\hline $\mathrm{Nr}$ & Item description & $n$ & $M$ & $\begin{array}{l}\% \text { fully } \\
\text { disagree }\end{array}$ & $\begin{array}{l}\text { \% slightly } \\
\text { disagree }\end{array}$ & $\begin{array}{l}\% \text { slightly } \\
\text { agree }\end{array}$ & $\begin{array}{l}\% \text { fully } \\
\text { agree }\end{array}$ & $\begin{array}{l}\% \text { not } \\
\text { apply }\end{array}$ \\
\hline 9 & $\begin{array}{l}\text { Game fosters } \\
\text { collaboration }\end{array}$ & 11 & 1.8 & 45.5 & 36.4 & 9.1 & 9.1 & 0 \\
\hline 10 & $\begin{array}{l}\text { Game increases flexibility } \\
\text { of collaboration }\end{array}$ & 11 & 2.0 & 36.4 & 36.4 & 18.2 & 9.1 & 0 \\
\hline 22 & $\begin{array}{l}\text { Game adequately } \\
\text { addresses critical } \\
\text { assessment each } \\
\text { others work }\end{array}$ & 11 & 2.4 & 27.3 & 18.2 & 45.5 & 9.1 & 0 \\
\hline 25 & $\begin{array}{l}\text { I liked to virtually } \\
\text { collaborate }\end{array}$ & 11 & 2.0 & 27.3 & 54.5 & 9.1 & 9.1 & 0 \\
\hline 34 & $\begin{array}{l}\text { I feel the effort to } \\
\text { collaborate by other } \\
\text { students was sufficient }\end{array}$ & 10 & 2.0 & 20.0 & 30.0 & 40.0 & 0 & 10.0 \\
\hline 38 & We collaborated well & 11 & 2.4 & 18.2 & 18.2 & 54.5 & 0 & 9.1 \\
\hline 44 & $\begin{array}{l}\text { Collaboration improved } \\
\text { quality of report }\end{array}$ & 11 & 2.3 & 27.3 & 27.3 & 18.2 & 18.2 & 9.1 \\
\hline 45 & $\begin{array}{l}\text { Game increased my } \\
\text { insight in perspectives }\end{array}$ & 11 & 2.4 & 9.1 & 45.5 & 36.4 & 9.1 & 0 \\
\hline 46 & $\begin{array}{l}\text { Game increased my } \\
\text { argumentation skills }\end{array}$ & 11 & 2.1 & 45.5 & 9.1 & 36.4 & 9.1 & 0 \\
\hline 47 & $\begin{array}{l}\text { Game increased my } \\
\text { negotiation skills }\end{array}$ & 11 & 2.1 & 45.5 & 9.1 & 36.4 & 9.1 & 0 \\
\hline
\end{tabular}

Table 3: Student scores on reports, both before and after virtual collaboration, as well as average scores for initial perspectives

\begin{tabular}{lccl}
\hline Student ID & Before & After & Initial perspective \\
\hline 1 & 23 & 60 & Governance \\
2 & 24 & 54 & Governance \\
3 & 23 & 55 & Ecological \\
4 & 27 & 60 & Ecological \\
5 & 17 & 47 & Governance \\
6 & 37 & 67 & Ecological \\
7 & 17 & 47 & Governance \\
8 & 10 & 58 & Governance \\
9 & 3 & 52 & Governance \\
10 & 21 & 51 & Ecological \\
11 & 20 & 50 & Ecological \\
12 & 17 & 47 & Governance \\
Avg both & 20 & 54 & \\
Avg $_{\text {ecol }}$ & 26 & 57 & \\
Avg gov $^{\text {gov }}$ & 16 & 52 & \\
\hline
\end{tabular}

show that students spend about the same time-on-task from both perspectives. The relative increase for students starting from the governance perspective (going from $M=15.86$, $S D=7.31$ towards $M=52.14, S D=5.46$ ) is slightly higher than for the group that started from the ecology perspective (going from $M=25.60, S D=6.91$ towards $M=56.60$, $S D=7.02$ ). This is in line with students' comments about the relative difficulty of understanding the governance sources, which are rare in their programme. We did find a significant 
$(p<0.05)$ difference with large effect for perspective on measures before collaboration ( $F$ ( 1 , $\left.11)=5.41, M S E=267.86, p=0.04, \eta_{p}{ }^{2}=0.35\right)$; the difference for perspective on measures after collaboration was found not to be significant $(F(1,11)=2.33, M S E=96.19, p=0.16$, $\eta_{p}{ }^{2}=0.19$ ). Finally, the overall quality of the reports before and after collaboration remained poor to average.

While assessing the quality of the reports, tutors observed a number of more qualitative results that also provide evidence for the contribution of collaboration. Increases between preliminary and final reports were to the largest degree attributable by gains in scores on the integration items of the correction model. For instances, an integrated map was distilled from information from both perspectives, information about known cultivation methods (ecological perspectives) was linked to existing legislation (governance perspective), and confrontation of perspectives led to better rethink the selection of most suitable shellfish species. Overall, it is the opinion of both tutors, that the conclusions could not be reached based on one perspective, or learning trajectory only.

\section{Student appreciation}

Appreciation of the virtual collaboration within the educational game was measured by a number of questionnaire items. The educational game was scored on average $(M=5.6)$ by 10 students, with six students grading 8, two grading 4, one grading 3 and one grading 8. Participants have indicated to prefer real life collaboration over virtual collaboration (see also score on item 25), although they see that online education does increase the flexibility of study. Table 3 shows that the appreciations of the contribution of the game to social skills (collaboration, negotiation, critical assessment), as well as its perceived contribution to professional competence yield rather mixed results. Especially, items 22, 46 and 47 yield rather mixed results, with the largest groups scoring either 'fully disagree' or 'slightly disagree'. Overall, these findings need to be interpreted as 'poor to average' appreciation of virtual collaboration. More qualitative comments made by students also indicate differences in appreciation, for instance, of the degree this serious game helped them to integrate both perspectives scientifically. Student X states 'I wonder if many students will really be able to really deepen their scientific understanding of both perspectives by studying this game', while student Z states 'It was really fascinating to deepen my understanding of the governance aspects which normally do not grasp my interest that much'. The second hypothesis on preference has to be declined: these students did not prefer virtual collaboration over real collaboration.

\section{Conclusions and discussion}

Preliminary results from our case study using an educational (serious) game 'Aquaculture' have shown that scripted collaboration indeed significantly improves the quality of learning output. Furthermore, students indicate that the game helped them gain more insight into the various perspectives that play a part for their professional development. It could be concluded from this study that collaboration within serious games can indeed improve learning about certain problem situations in the workplace, according to new modes of more active and experiential learning as were introduced in the introduction. It could not be concluded that students prefer these kinds of virtual learning environments over more traditional face-to-face settings of collaboration.

Further research into scripted collaboration and serious gaming therefore seems justified. However, students' appreciation of this way of collaborating was poor to average. Interpreting the more qualitative comments they made, we assume that this largely has to be contributed to their preference for real life collaboration (expressed both before and after studying the game), insufficient prior knowledge about the governance part, and the fact they are not yet accustomed to the 
new role of serious games in education. Students do see potential for new media to make education more flexible (freedom to study at your own pace, place and time).

There were a number of serious constraints to this study, which had to run in the context of a development project. First of all, students did not really work together as persons within the game, but 'collaborated' with a non-playing virtual colleague. Virtual collaboration between two or more (real) persons would surely have felt much more authentic and motivating. Secondly, for the measured learning gains, we did not control for the contribution of time-on-task. After collaboration, students could spend another amount of hours (roughly $25 \%$ of total study load) on the game and further elaborate the report. The relative low amount of additional time, however, can not fully wash away the relative high gain that was measured. Thirdly, students were allocated to their individual perspective, instead of making this choice themselves. This might have lowered their commitment and motivation. In more controlled experimental settings, preferably in other domains and with higher amounts of participants, these limitations could be addressed.

The collaboration script seems to be an interesting didactical scenario (or pattern of gameplay) to be further examined in serious gaming research, also, because the complexity and costs of gameplay design and game development could be decreased if standardised methods, tools and components, and reusable design patterns would become available and could be flexibly reused. Design patterns can describe salient and re-occurring phenomena in the gameplay (ie, collaboration patterns), allow for flexible and modularised implementation, and provide a common vocabulary across domains. The collaboration pattern (script) we described produces code that can be instantiated in different settings and domains (where negotiation and conflicting perspectives play a role), and deployed in different runtime environments for serious gaming (Bjork \& Holopainen, 2004). One can think of alternative ways of implementing the desired collaboration script, for example by defining two roles, one for each perspective. In our case study, the tutor, as 'case run manager', had to appoint students manually to one of both roles, having more control but restricting the students' freedom, in contrast to the alternative solution.

Gameplay for complex learning inherently is complex, and development requires expertise from both domain experts, pedagogical designers, text writers and software developers (Westera, Nadolski, Hummel \& Wopereis, 2008; Zyda, 2007). Furthermore, serious game development so far remained fragmented and tends to combine approaches on a rather ad hoc basis, and hardly reuses successful approaches, components or design patterns from existing and successful games (Bogost, 2007). Finally, the amount of empirical evidence on the effectiveness of educational games stays limited (Becker, 2006). Further research should be aimed at more evidencebased studies and other design patterns. At least for one of the potential design patterns does this study provide promising results and a reusable game pattern to be duplicated in other settings.

\section{Acknowledgements}

This study was carried out within the Skills Laboratories project, funded by SURF foundation (http://www.surffoundation.nl/en)

\section{References}

Becker, K. (2006). Pedagogy in commercial video games. In D. Gibson, C. Aldrich \& M. Prensky (Eds), Games and simulations in online learning: research and development frameworks (pp. 21-47). Hershey, PA: IDEA Group.

Beers, P. J., Boshuizen, H. P. A. \& Kirschner, P. A. (2003). Agreeing to disagree: perspective, negotiation and common ground. In P. A. Kirschner (Ed.), The Social psychological dimension of social interaction and the 
effects of cultural backgrounds in CSCL. Padova, Italy: EARLI. Symposium conducted at the 10th EARLI Conference.

Bell, B. S., Kanar, A. M. \& Kozlowski, S. W. J. (2008). Current issues and future directions in simulation-based training in North America. International Journal of Human Resource Management, 19, 8, 1416-1434.

Bjork, S. \& Holopainen, J. (2004). Patterns in game design. Hingham, Massachusetts: Charles River Media.

Bogost, I. (2007). Persuasive games. Cambridge, MA: MIT Press.

De Freitas, S. (2006). Learning in immersive worlds. Joint Information Systems Committee (JISC). Retrieved December 10, 2009, from http://www.jisc.ac.uk/media/documents/programmes/elearninginnovation/ gamingreprt_v3.pdf

De Wever, B., Valcke, M. \& van Winckel, M. (2003). The impact of 'Structure' in CSCL environments: a study with medical students. Paper presented at CSCL 2003 Doctoral Consortium. Retrieved July 14, 2009, from http://www.intermedia.uib.no/cscl/dic/files/dewever.pdf

Fullerton, T., Swain, C. \& Hoffman, S. S. (2008). Game design workshop: a play-centric design approach to creating innovative games (2nd ed.). Burlington: Elsevier.

Gee, J. P. (2003). What video games have to teach us about learning and literacy? New York: Palgrave MacMillan.

Gunawardena, C. N., Carabajal, K. \& Lowe, C. A. (2001). Critical analysis of models and methods used to evaluate online learning networks. Seattle: AERA.

Gunawardena, C. N., Lowe, C. A. \& Anderson, T. (1997). Analysis of a global online debate and the development of an interaction analysis model for examining social construction of knowledge in computer conferencing. Journal of Educational Computing Research, 17, 4, 395-429.

Hämäläinen, R., Oksanen, K. \& Hákkinen, P. (2008). Designing and analyzing collaboration in a scripted game for vocational education. Computers in Human Behavior, 24, 2496-2506.

Jeong, H. \& Chi, M. T. H. (2000). Does collaborative learning lead to the construction of common knowledge? Retrieved July 9, 2009, from http://www.ircs.upenn.edu.edu/cogsci2000/PRCDNGS/SPRCDNGS/ posters/jeo_chi.pdf

Kiili, K. (2007). Foundations for problem-based gaming. British Journal of Educational Technology, 38, 94-40.

Michael, D. \& Chen, S. (2006). Serious games: games that educate, train and inform. Boston, MA: Thomson Course Technology.

Nadolski, R. J., Hummel, H. G. K., Van den Brink, H. J., Hoefakker, R., Slootmaker, A., Kurvers, H. et al. (2008). EMERGO: methodology and toolkit for efficient development of serious games in higher education. Simulations \& Gaming, 39, 3, 338-352.

Owen, M. (2000). Structure and discourse in a telematic learning environment. Educational Technology \& Society, Retrieved December 2, 2009, from http://ifets.ieee.otg/periodical/vol_3-2000/b04.html

Prensky, M. (2006). Don't bother me Mom, I'm learning: how computer and video games are preparing your kids for 21st century success and how you can help. Minnesota: Paragon House.

Rayburn, E. M. (2007). Applying simulation experience design methods to creating serious game-based adaptive training systems. Interacting with Computers, 19, 2, 206-214.

Shaffer, D. W. (2006). How computer games help children learn. New York: Palgrave MacMillan.

Strijbos, J. W. \& Martens, R. L. (2001). Coördinatieprocessen tijdens computerondersteund samenwerkend leren [Coordination processes during CSCL]. In P. A. Kirschner (Ed.), Factoren die collaboratief leren beinvloeden [Factors that influence collaborative learning]. Open University of the Netherlands: Onderwijs Heerlen.

Van Bruggen, J., Kirschner, P. A. \& Jochems, W. (2002). Representation of argumentation in CSCL and management of cognitive load. Learning and Instruction, 12, 1, 121-138.

Weinberger, A., Ertl, B., Fisher, F. \& Mandl, H. (2005). Epistemic and social scripts in computer-supported collaborative learning. Instructional Science, 33, 1, 1-30.

Westera, W., Nadolski, R. J., Hummel, H. G. K. \& Wopereis, I. (2008). Serious games for higher education: a framework for reducing design complexity. Journal of Computer Assisted Learning, 24, 50, 420-432.

Zyda, M. (2007). Creating a science of games. Communications of the ACM, 50, 7, 27-29. 